\title{
Shadow Education in Uzbekistan: Teachers' Perceptions of Private Tutoring in the Context of Academic Lyceums
}

\author{
Sherzod Khaydarov \\ Westminster International University in Tashkent
}

\begin{abstract}
Private tutoring is a globally widespread phenomenon which can be associated with marketization and privatization. After the breakdown of the Soviet Union, the transition to a free-market economy in Uzbekistan facilitated the rise of informal private sector in public education. This in turn has affected mainstream schooling in many ways and changed the face of education. Considering socio-economic transformations in the country, the theory of hidden privatisation by Ball and Youdell (2007) is employed to analyse different facets of informal privatization in the form of shadow education. Drawing on 24 face-to-face interviews with teachers, (vice) principals and students and student questionnaires, this article examines the nature and scale of private tutoring as well as teachers' perspectives on the influence of tutoring on teaching and learning process. The findings demonstrated that teachers' overall attitudes towards private tutoring were positive and teachers mostly considered tutoring as an indispensable part of teaching and learning process. The most significant finding was that the scale of tutoring was exceptionally high $(95 \%)$ in academic lyceums. The pervasiveness of the phenomenon is associated with entrance examinations, which increased the dependency of teachers and students on tutoring. The article concludes by elucidating how the emergence of shadow education in academic lyceums resulted in the change of the nature of mainstream schooling and the transformation of teacher identities.
\end{abstract}

Keywords: shadow education (private tutoring), teachers' perception, academic lyceum, hidden privatization, Uzbekistan

Private tutoring (PT), as a new form of privatization of education, has grown at a fast pace over the few decades all over the world and has become a billion-dollar business in the global market (UNESCO, 2017). The trend is especially significant in some East Asian countries, where the phenomenon has been known for longer periods as well-structured establishments with specific names, such as 'juku' in Japan, 'hagwon' in South Korea, 'buxiban' in Taipei (China), and 'kewai fudao' in Mainland China (Bray \& Kwo, 2014; Liu, 2015). Although diverse tendencies are visible globally, Bray, Kwo, and Jokić (2015) asserted that research on PT is less progressed than the actual development of the issue. The investigation of the phenomenon is largely focused in East and Southeast Asia, such as Hong Kong SAR, China, South Korea, Taiwan, Japan, Singapore, Sri Lanka, and India. Studies and investigations have also spread across African, European, North and South American countries as well as other parts of Asia (Wang \& Bray, 2016), although the research is not as widespread. 
Silova and Bray (2006a) identified different trends of PT across former socialistic countries, grouping them according to their similarities: Central and South-Eastern Europe, the Soviet Union, and Mongolia. The market for PT among these countries developed vastly after the collapse of socialism in the 1990s, following political, economic, and social transformations (ibid). Amid post-Soviet countries, similar tendencies can be observed in the Caucasus and Central Asian countries. However, there are only a few researchers who have touched upon the phenomenon in these countries (Bagdasarova \& Ivanov, 2009; Kalikova \& Rakhimzhanova, 2009; Kazimzade \& Lepisto, 2010; Kodirov \& Amonov, 2009; Pussurmanova, 2017; Silova, 2010) and none of these studies have addressed the issue in Uzbekistan. Silova (2009b) emphasized the scarcity of data on PT in her research on Central Asian countries and despite her attempts, she could not gain access to data collection in Uzbekistan ( $p$. 47). Bray and Kwo (2014) and Silova (2009a) provided a few references about the country, but those data are not based on actual research. Thus, there is a need to explore this phenomenon empirically in the context of Uzbekistan.

PT has attained a great significance in public education especially in countries which experienced a transitional economy. Following the breakdown of the Soviet Union, the transformational recession in Uzbekistan had serious repercussions on social life. The reduction of funding in education as well as high rate of inflation was reflected in the decrease of teacher salaries and the quality of education. The financial hardships forced teachers to engage in PT to supplement their salaries and this enabled hidden privatization to enter the mainstream schools in the form of shadow education. This eventually caused the gradual expansion of PT market in the country and similar trends were observed in neighboring countries, such as Kazakhstan, Kyrgyzstan, and Tajikistan (Silova, 2009a).

Despite its short history, the spread of PT has been rapid and enrolment rates have significantly increased in recent years. Outside school PT has become a main competitor of public education, while inside school premises, the trend for teachers has shifted from a survival mechanism to an imperative part of teacher identity. For parents and children, on the other hand, PT has become the only option to meet their individual needs. Considering these changes, the study intends to explore how a fast-growing shadow education market influences mainstream schooling in Uzbekistan.

The study aims to identify the scale, types, intensity, mode, and costs of PT as preliminary data and explore the potential effects of PT on the process of teaching and learning from the viewpoint of teachers. As Bray and Kobakhidze (2015) asserted, there are few studies only addressing teacher identity and challenges associated with PT from teachers' perspectives. With this in mind, this research considers the dual roles of teachers and their contradicting beliefs: professional/moral values versus market values as perceived by teachers and teacher-tutors. 
The study is concerned with academic lyceums (affiliated with higher education institutions) at upper-secondary education level in which the phenomenon of PT is more visible, since lyceums prepare students for the entrance exams at higher education (HE) institutions. Studies also have shown that tutoring is more widespread in urban areas (see Bray, 2009; Bray \& Kwok, 2003), hence it is worthwhile to study the phenomenon in the context of lyceums as they are mostly located in big cities. Grade 12 students were selected for this study as it is more likely that students at transitional periods take more PT (Bray, 2009).

Academic lyceums were formed in 1997 as three-year specialized secondary education which were supposed to play the role of 'elite schools' to assist bright students to get into higher education. Secondary school students (after finishing Grade 9) enrol in academic lyceums through the entrance examinations held by State Testing Centre. Since the academic year of $2017 / 18$, the period of schooling at lyceums has been reduced to two years following the shift from $\mathrm{K} 12$ to a former 11-year education. The number of lyceums has also been reduced more than twofold and currently 68 lyceums are in operation in the country. ${ }^{1}$

\subsection{Definition and conceptual framework}

The definition of shadow education is based on Bray's (1999) interpretation which is associated with three characteristics of PT: being supplementary, fee-charging and academic. The metaphor of 'shadow education', which is widely acknowledged among researchers, refers to the content in the 'shadow' that mimics the curriculum of conventional teaching at schools (Bray, 1999).

Investigating the phenomenon of shadow education is rather complex due to its delivery on an informal basis (Bray, 2006). The trend of the shadow market in newly emerged countries, such as Uzbekistan, can be quite similar to the patterns observed worldwide because of the influence of globalization and free marketization. However, it is likely that the perceptions of stakeholders might vary from the existing literature of global discourses owing to cultural, political, economic and social settings.

Bearing in mind these factors, the study employs the theory of 'hidden privatization in education' by Ball and Youdell (2007). In their study, the authors classified privatization into two types: endogenous and exogenous (See Figure 1). In the endogenous type, new concepts, techniques, and practices are introduced into public education from the private sector and the public sector performs "more like business or business-like" (p. 16). Whereas, in the exogenous type, the private sector itself participates in the provision of education along with designing and managing programs. The authors categorized PT as an exogenous type of privatization and defined as a mechanism which complements the public sector by providing education for private profit. The authors paid very little attention to PT and did not discuss the

See https://edu.uz/uz/pages/secondary-special-and-vocational-education. 


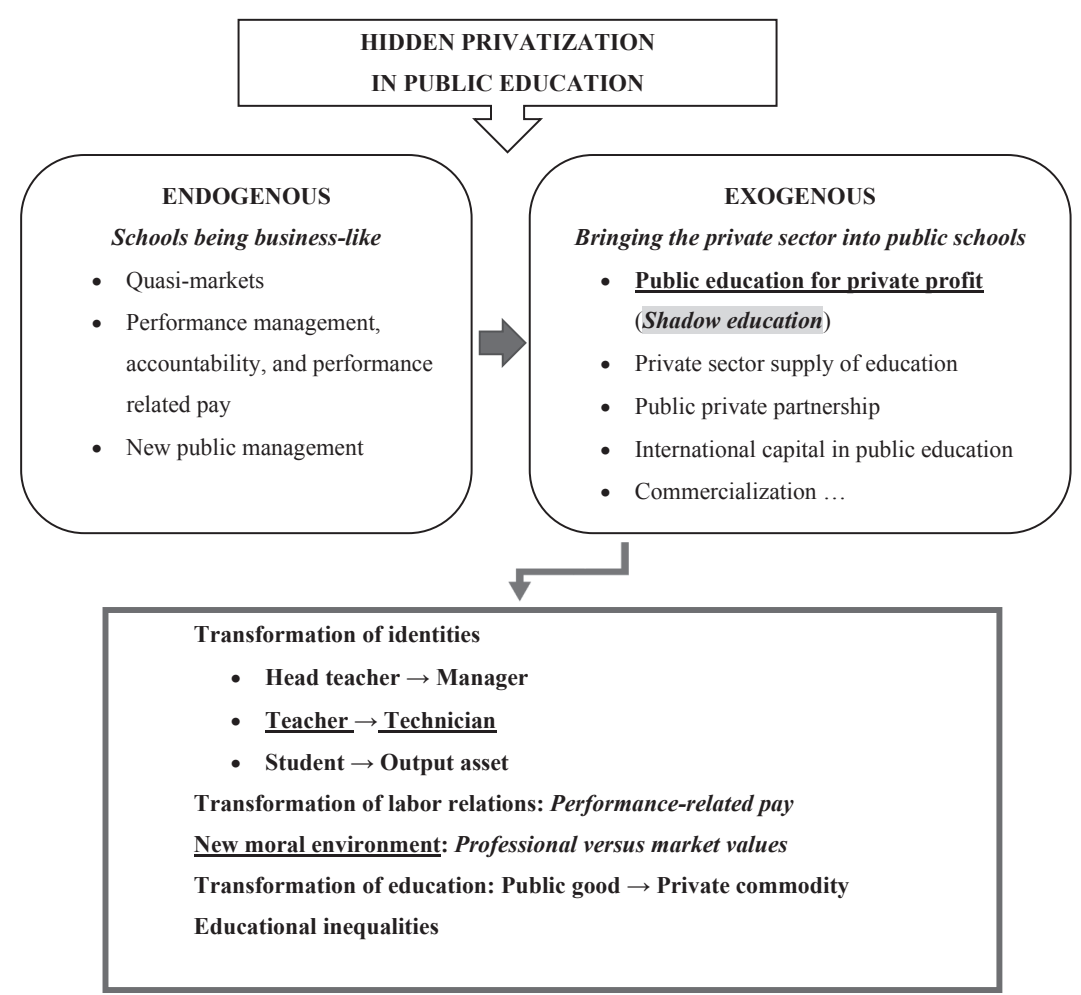

Figure 1 Hidden privatization in public education

(schematic depiction by S. Khaydarov based on the work of Ball \& Youdell, 2007)

Table 1 Professional and market values (Ball \& Youdell, 2007, pp. 52-53)

\begin{tabular}{ll}
\hline Professional values & Market values \\
\hline $\begin{array}{l}\text { Individual need } \\
\text { (schools and students) }\end{array}$ & $\begin{array}{l}\text { Individual performance } \\
\text { (schools and students) }\end{array}$ \\
$\begin{array}{l}\text { Commonality } \\
\text { (mixed-ability classes, open access, inclusion) }\end{array}$ & $\begin{array}{l}\text { Differentiation and hierarchy } \\
\text { (streaming, selection, exclusion) }\end{array}$ \\
Serves community needs & Attracts 'clients' or 'customers' \\
Emphasis on resource allocation to those with & Emphasis on resource allocation to those \\
greatest learning need & considered more able \\
Collectivism & Competition \\
(co-operation between schools and students) & (between schools and students) \\
Broad assessments of worth based upon & $\begin{array}{l}\text { Narrow assessments of worth based on } \\
\text { varieties of academic and social qualities }\end{array}$ \\
contribution to performance indicators \\
The education of all children is held to be & The education of children is valued in relation \\
intrinsically of equal worth & to costs and outcomes
\end{tabular}


type of tutoring that is provided by teachers. Nevertheless, their concepts can be similarly applied to evaluate the impact of tutoring on teachers' teaching activity in the context of lyceums. In particular, the concept of changing teacher professional values into market values (Table 1) can be utilized as a framework to assess teachers' attitudes regarding their teaching and tutoring roles.

\section{PT in the context of Uzbekistan: History and regulations}

The extent of PT is largely dependent on the principles and regulations of the education system. The absence of legal guidelines and lax controls may hinder education at mainstream schools as this enables teachers to engage with tutoring themselves.

Concerning the history of PT in Uzbekistan, initial forms of tutoring existed even during the Soviet Union in a hidden form among few families, but it was muted as the private sector was strictly banned by officials (Silova \& Bray, 2006b). However, the market for PT became noticeable when the current centralized test-based high-stakes entrance examination was introduced in $1994^{2}$ to replace pre-existed university-based admissions. The majority of students were unfamiliar with testbased examinations and this shift generated the demand for PT as students assumed tutoring to be efficient for coping with transformations in the education system (Silova, 2009c).

Similarly, after the independence, the transition from socialism to a free market economy facilitated the emergence of the private sector in education as well. However, establishing private schools were banned in 1993 amid the fear of arising extremist groups (Hays, 2008). To sustain the needs of students, test-oriented preparatory courses were established under each university which were coached by university teachers (Silova, 2009b). The fees were considerably low, usually contracted for the whole year for certain examination subjects relevant to each university. Tutoring centres, by contrast, were very rare. PT was therefore done mainly by teacher-tutors.

Currently, there are no formal regulations concerning teachers' engagement in PT in Uzbekistan and this jurisdiction characterizes laissez faire practice in which "[t]he school and education authorities do not have policies on the matter, leaving decisions to the teachers themselves and to their clients" (Bray \& Kwo, 2014, p. 45). PT is considered as a form of entrepreneurship and officially teachers are neither restricted nor imposed a tax for offering tutoring services. Thus, most teachers provide tutoring on an informal basis. According to the previous Education Law (1992), teachers were given the right of performing "an individual pedagogical activity" (Article 32), but the current Educational Law does not include any reference regarding private tutoring. However, following the Presidential Decree No. 1875 on December 12, 2012, the Department of Foreign Languages Proficiency Assessment

2 Based on the Decree of the Cabinet of Ministers of the Republic of Uzbekistan No. 258 (1994). http://dtm.uz/page/view/mode/the-history-of-dtm. 
86 was established as part of the State Testing Centre and it started to license both teachers and tutoring centres with qualification of tutoring foreign languages. It was officially announced that teachers of foreign languages are required to obtain language proficiency certificates to offer tutoring services, however this regulation is rarely observed in practice. Therefore, the engagement of teachers in PT remains hidden and unnoticed.

\section{Studies on teachers' perspectives}

PT has been examined by different authors for varied purposes. A considerable amount of studies on PT addressed the nature, demand, drivers, impacts, and regulations of the phenomenon. Through the literature review, a few studies were found on teachers' perspective on shadow education (Bray \& Kobakhidze, 2015; Kobakhidze, 2014, 2018; Popa \& Acedo, 2006; Sun, 2017; Wang and Bray, 2016) which illustrate insights of the phenomenon in three contexts only, namely in Romania, Georgia and Hong Kong.

Popa and Acedo (2006) investigated teacher professionalism in relationship with tutoring in Romania and their interviews with high school teachers illuminated how teachers' engagement in tutoring helped regenerate professional identity and reestablish teacher authority. By contrast, Kobakhidze (2014) studied corruption risks associated with tutoring, dual roles of teachers, challenges and moral dilemmas related to tutoring their own students in the context of post-Soviet Georgia.

Unlike the studies mentioned above, Wang and Bray (2016) examined the viewpoints of teachers regarding the role of supplementary PT as received by their existing students in Hong Kong. Their study revealed significant findings which demonstrated opposing attitudes of teachers towards PT and their feelings on social stratification against holistic education in the context of examination-driven culture. In a similar context, but at the primary school level, Sun (2017) studied Chinese and English teachers' attitudes towards PT taken by their students. Although the study found some interesting aspects of teacher attitudes on the implications of PT, the reasons behind conflicted attitudes were not questioned fully.

Kobakhidze's (2018) study, on the other hand, explored the phenomenon from the teacher-tutors' perspective focusing on teachers' professional beliefs and values regarding morality and corrupted practices. She found sociological concepts more suitable to study the behaviors of teacher-tutors due to the informal nature of PT in Georgia. One of her major contributions was to explore the shadow market from the perspective of economic sociology, which helped to draw a comprehensive picture of the phenomenon with contextual nuances in post-Soviet Georgia. 


\section{Research method}

The study employed a mixed method to examine the nature of PT and teachers' perceptions of the phenomenon. For data collection, the priority-sequence model by Morgan (1998, as cited in Teddlie \& Tashakkori, 2003, p. 27) was used as a framework. Morgan introduced two groups of decision rules in his model to merge quantitative and qualitative methods for information gathering during the fieldwork. One is deciding the priority of the methods and the other is deciding on the sequence of the methods. For studying the implications of PT, the researcher adopted the framework which comprises 2 phases.

For the quantitative part, a two-page questionnaire was employed to elicit preliminary data about the enrolment rates in PT and identify the scale of teachers who are tutoring their students. The scarcity of the information on PT in Uzbekistan necessitated the inclusion of quantitative data to illustrate contextual features of the phenomenon and corroborate the findings of the qualitative part.

A substantial part of the data concerning PT experiences was gathered through semi-structured individual interviews in the Uzbek language. Separate interview protocols were prepared for each target group with organizational and preliminary notes. Teachers were a priority group; therefore, teachers' interview protocol had an extensive list of open-ended questions that are comprised of nine thematic topics. By contrast, interview questions for students and principals were limited to five topics. Interview questions were mainly adapted from Bray and Kwo (2015) and some sections that are related to teacher-tutors were borrowed from Kobakhidze (2018).

The author mostly followed the interview guide approach (Patton, 1980, as cited in Cohen, Manion, \& Morrison, 2007, p. 353), in which the topics and research concerns were identified in advance and questions were asked flexibly during the interview. This approach maintained the richness of the data as interviews were relatively conversational and it gave the researcher more flexibility whether to add or omit questions due to the experience of interviewees (ibid).

This study is chiefly based on teacher interviews. Yet, the data were triangulated with interviews of principals, vice-principals and sampled students. For research validity, the author grounded the study on Onwuegbuzie and Johnson's (2006) inside-outside legitimation (p. 58). The author received assistance from peers and an MEd supervisor from the University of Hong Kong, which helped to observe the phenomenon from an outsider perspective, while being an insider at the research site helped the researcher understand the phenomena from a local perspective. The convergence of these etic and emic viewpoints corroborated research outcomes.

\subsection{Selection of research site}

The target population of the study was students and teachers of selected academic lyceums in Samarkand city. Samarkand, the author's hometown, was chosen as a research site for two reasons: first, the setting was convenient in terms of time 
88 and financial aspects; secondly, the viability of gaining access was an important factor.

According to the regional educational board, 14 academic lyceums were operating in Samarkand region as of $2017 .{ }^{3}$ The total population of lyceums amounted to 10,402 students (3,340 of them were Grade 12 students) and 935 teachers in the 2017-2018 academic year. Bearing in mind the availability of limited time, the study is restricted to two lyceums, which can represent general features in the region. The lyceums were selected based on convenience sampling: the first lyceum was the researcher's former workplace, while the principal of the second lyceum was his former colleague.

Academic lyceums had been administered by regional Educational Boards by the year of 2017. However, following the President's Decree No. 2829 in 2017, the task of supervising academic lyceums was transmitted to the respective HE institutions they had been bound to. As for selected lyceums, both lyceums have a few distinct features, which are presented in Table 2.

Table 2 Characteristics of the research sites

\begin{tabular}{|c|c|c|}
\hline & Academic lyceum 1 & Academic lyceum 2 \\
\hline Affiliation & $\begin{array}{l}\text { Samarkand Institute of Economy } \\
\text { and Service }\end{array}$ & Samarkand Institute of Agriculture \\
\hline Location & Samarkand city & Samarkand city \\
\hline Number of students & 1343 (mostly from urban areas) & 737 (mostly from rural areas) \\
\hline $\begin{array}{l}\text { Number of Grade } 12 \\
\text { students }\end{array}$ & 452 (138 females) & 242 (61 females) \\
\hline Number of teachers & 96 (50 females) & 71 (39 females) \\
\hline Courses & $\begin{array}{l}\text { Economics, Foreign languages, } \\
\text { Social studies, Natural sciences }\end{array}$ & $\begin{array}{l}\text { Natural sciences, Technical } \\
\text { sciences, Economics, Social } \\
\text { studies, Foreign languages }\end{array}$ \\
\hline
\end{tabular}

\subsection{Sampling and recruitment}

The research utilized a multilevel sequential design for sampling based on Onwuegbuzie and Collins' (2007) mixed sampling framework. This framework is suitable for selecting two or more sets of samples for quantitative and qualitative phases. In the current research, the quantitative part involved the sampling of students, while the qualitative part utilized the sampling of teachers, principals, vice-principals as well as students.

For the questionnaire, Grade 12 classes were randomly selected from each lyceum and passive consent forms were distributed a week before the survey. Then,

3 Source: www.samusspo.uz/about/general_info. 
based on the results, 50 to 60 students from each lyceum were selected based on cluster sampling. In total, 109 students were involved in the survey.

For interviews, teachers were drawn from the same lyceums through purposeful (to get broad range of teachers) and snowball sampling. Considering the characteristics of teachers, such as gender, experience, age and teaching subjects, eight teachers were selected from each lyceum for individual interviews. For the cross-verification of teacher interviews, four students from each lyceum were selected from the questionnaire sample. Finally, a principal and vice-principal of each lyceum were interviewed to reinforce the data. In total, 28 individuals were interviewed during the survey.

\section{Findings}

\subsection{The scale and nature of PT}

The findings of the questionnaire showed that $95 \%$ of lyceum students were receiving or had received PT over the last 12 months prior to the fieldwork. There was very little difference in the participation rates of PT between the two sampled lyceums, indicating that the phenomenon could be significant in other lyceums too. Although lyceums are often regarded as institutions with high academic excellence, nearly all students had to regularly attend tutoring classes after the lessons and this means that "PT is actually becoming a substitute for regular schooling rather than just a shadow" (Bray and Kobakhidze, 2014, p.15).

As for the delivery of PT, the questionnaire findings indicated that most students received tutoring in large (65\%) and/or small (63\%) groups, while one-to-one tutoring (only $17 \%$ of respondents) was much less common. Popular PT subjects among students consisted of Uzbek language, English, Mathematics, and History, whereas science subjects such as Physics, Chemistry, Biology were less popular. This is largely associated with the demand of students and "[t]he subjects in greatest demand are ones required by examination systems" (Bray, 2006, p. 520). Therefore, as Bray (2006) stated, tutoring in subjects such as national languages and Mathematics were more common.

Regarding the dominant type of PT, all the teachers, except one, specified lyceum teachers as primary providers of PT for the students of academic lyceums. The findings of the questionnaire also indicated that students predominantly received tutoring from lyceum teachers, however, the percentage of tutoring centres was a bit higher in AL2. Although students did not specify the name of tutoring centres they were going to, some of the teachers remarked that students were mostly attending the tutoring centre that was newly established within the premises of the lyceum. The administration also approved that the students were receiving tutoring either from teachers or the tutoring centre of the lyceum. 
The share of other tutoring centres or independent tutors was also significant. Half of the interviewees remarked on the growing influence of tutoring centres, due to their advertisements and promotional deals. One of the teachers asserted that tutoring centres were trying to entice students in many ways in response to stiff competition with other providers of tutoring. Likewise, another one stressed that tutoring centres were becoming their main competitors in terms of tutoring, but claimed that most students still chose lyceum teachers.

One of the interesting findings was that nearly all students $(97 \%)$ received PT to prepare for national entrance examinations. Students mostly received tutoring in two or three subjects as examinations are based on a combination of three different subjects. This suggests that students took PT primarily for an 'enrichment' strategy (Bray 2006; Bray \& Kobakhidze, 2014; Silova, 2009b) to manage with high-stakes examinations. Additionally, teachers in the study asserted that students did not participate in PT for 'remedial' or 'reinforcement' purposes (Baker \& Le Tendre, 2005; Bray, 2006; Silova, 2009b) which was in line with the students' responses in the questionnaire and interviews. These findings suggest that students are less concerned about their lyceum lessons but concentrated more on PT to pass entrance examinations.

\subsection{Teacher attitudes}

When teachers were asked about their feelings regarding students receiving PT in the subjects that they teach, almost all teachers felt 'positive', 'happy' or 'glad', while the rest did not mind their students seeking PT. The teachers approved their students' use of PT either because they thought PT was more helpful in supporting low-achieving students or because they regarded PT as a necessity for students' academic achievement. No one mentioned negative aspects of PT and teachers were likely to be supportive of PT as they were providing tutoring too.

Many teachers felt sympathetic towards students due to the increasing competition and complexity of tests. Even as parents, the teachers indicated that they would encourage their children to receive PT. Although it was a slight exaggeration, a Physics teacher claimed that students were capable of solving not more than $10 \%$ of entrance examination tests without PT. Similarly, a History teacher, responded to the question as follows:

In the current situation, I regard PT as positive and I think it is highly necessary. The knowledge given in lyceum is not enough and I don't believe the students who rely on regular schooling can pass entrance examinations.

An Uzbek language teacher was even curious about how many students were taking PT from her subject:

Whenever I am for the first time in a class I ask how many students are receiving PT and try to find out the reasons if any students are not taking tutoring. If most students 
are receiving, I'll become happy, because PT makes them busy with studying and they won't forget the subject.

Likewise, a Geography teacher, who held relatively negative opinions of PT, expressed that he would be delighted to see students receiving PT from his subject, not because he thought PT was helpful for his teaching, but because students would show an interest in studying his subject rather than regarding it as a secondary subject.

Only one teacher reported that he encouraged students to study independently and believed that students could manage without PT if they kept studying regularly over the period. However, he asserted that not all students would study diligently by themselves, therefore he thought PT to be helpful for those who could not cope with regular lessons.

\subsection{Teachers as tutors}

Although most teachers maintained a positive stance on PT throughout the interview, they had difficulty articulating their feelings about their tutoring roles. Some teachers considered providing PT a 'good thing', a 'normal situation', an 'easier' task or even an 'inspiring job' and they were pleased to hold the role of tutors. To some extent, they had enough reasons to claim so, as they pointed out financial advantages, professional development and enhancing their reputation as factors of a stimulus.

However, by no means were all teachers satisfied with their double roles, as some of them considered holding two roles time-consuming, exhausting and stressful. For instance, a History teacher specified her thoughts on tutoring as follows:

I think the motivation for doing PT derives from financial needs, in the first place. I hear most teachers complaining about their wages. They say 'If we had enough salary, we would not spend so a great deal of time and channel our efforts into PT, instead we would work on ourselves and get prepared for lessons'. And I wish the same too...

She was not only the one who mentioned the salary as the primary driving force of doing tutoring. A few other teachers and even principals acknowledged that teachers needed to provide tutoring to augment their meager income. However, in return, they had to sacrifice their strength and free time (and even partially, their working time) for the sake of PT.

Half of the teachers expressed some regret over the time spent providing PT. A History teacher reported that he sometimes felt embarrassed when he could not make time for teachers' and parents' meetings or other kinds of organizational work, whereas an Uzbek language teacher, who seemed to 'obtain energy from tutoring', instead worried more about her family time as she explained: "The only thing I regret about PT is my family time. I could have spent that time with my children. They need more care." By contrast, an English language teacher shared her feelings about the complexities of performing mixed roles: 
Sometimes, as a teacher, I feel bad for it because there were times I could not prepare for lyceum lessons. ... I try to keep my teaching and tutoring roles in balance. If you disregard your main duty, it certainly affects your reputation, and eventually, it influences your tutoring too, ... Sometimes, it depends on my mood and the environment in the classroom. There were times I paid more attention to PT. But in general, I put lyceum lessons in the first place.

Kobakhidze (2018) elucidated some subtle nuances of teacher and tutor roles and identities in the post-Soviet context of Georgia. The teachers in her study often expressed confusion when it came to defining their identities as they had formed a new identity with 'blurred boundaries between teaching and tutoring' (p. 114). In the context of Uzbekistan, signs of the same tendency were visible, but teachers failed to discern negative aspects of their acquired new role:

If to talk about PT, of course, it may have many negative aspects, but in the current situation, as teachers, we don't realize them, we don't see them. We only see positive sides, because we mostly look at the results in students' performance. (Geography teacher)

The teachers reflected in the same way when they were asked about tutoring their own students. Among 16 teacher-interviewees, only 2 of them were not engaged in tutoring and all of the remaining teachers acknowledged that they tutored their students. Half of the teachers considered tutoring their students as normal or positive and asserted that it did not have any negative impact. Others did not know how to respond and avoided commenting. Only one teacher considered such a case as 'not a good thing' and explained that "it causes irresponsibility and inattentiveness in students who are receiving tutoring from their teachers, and their attention will be on PT as they know that the teacher will explain the topic broadly during PT".

These responses show that there is a lack of awareness on teacher and tutor identities and most teachers viewed tutoring as part of their main job. However, the main challenge was how to keep the balance between the two roles as the majority of teachers were "juggling between tutoring and teaching" (Kobakhidze, 2018, p. 157) but not caring much about the consequences.

\subsection{Influence of PT on teaching}

With regards to the influence of PT, half of the teachers responded that tutoring made their teaching easier, four teachers stated that it caused difficulties, two teachers remarked there was no influence, while the other two teachers had mixed feelings.

Majority of teachers regarded PT as a means of developing their professional competences, i.e. fostering knowledge, increasing pedagogical experience, and enhancing test solving skills. Therefore, they had professional satisfaction from PT. This was clearly elaborated by an Uzbek language teacher: 
PT makes my job easier because I work a lot on myself. I prepare only lesson plans for lyceum lessons. When I see the topic, I know everything, what to teach and how to approach, so there is no need for the revision.

Seemingly, it was a common perception among teachers to regard PT as a part of the preparation for regular lessons. Similarly, PT was viewed as a way of preparing for the tests of State Inspection for the Quality in Education under the Cabinet of Ministers. Principal interviews also confirmed that teachers with PT were more successful in attestation screenings.

Furthermore, some teachers noted that PT enhanced the learning environment in the classroom. For instance, a Mathematics teacher asserted that PT improved students' understanding of the subject and helped his lessons go smoother. Other teachers observed that students became more active and demanding after receiving tutoring, and therefore accepted that PT was beneficial to their teaching.

However, the interviews also illuminated multiple problematic cases related to PT. The respondents provided some undesirable examples from their own experiences that provoked the discussion of the issue. To illustrate, an Astronomy teacher opposed the trend of studying only two or three subjects to gain admission into $\mathrm{HE}$ institutions. He criticized students focusing only on specialized subjects, which fostered the notion in students that other subjects were as if "secondary subjects". He also criticized students trying to do their tutoring assignments in a hidden way during the class.

Another experienced Mathematics teacher shared her experience of tensions that arose with her students when tutoring was provided by other tutors:

When I started teaching Mathematics, I realized that most of the students didn't understand the concept of the subject. They were taught to find the answer with a formula book. They were able to solve problems with shortcut tips but could not explain the process. I struggled a lot and I had to teach the basics first. ... Some students didn't like my approach and we became in conflict. If I had taught myself, it'd have been easier...

It seems not only experienced teachers but also young teachers could not tolerate when students prioritized their tutors' teaching practices. An English language teacher, who was ambivalent about PT, had quite similar experiences with her students. She noticed her students evaluated her lessons and compared her teaching with their tutors'. They then became negligent or inattentive when they mastered the topics in PT ahead of time. She also faced difficulties with planning lessons and materials that matched the different levels of students and thought that PT expanded the gap between students' knowledge even more.

Similarly, an English language teacher expressed mixed feelings towards PT. She considered PT to be positive in terms of strengthening students' knowledge but admitted negative impacts of tutoring on regular classes too in terms of additional tasks: "As a teacher and a tutor I am aware if I give numerous tasks to students during PT, they'll do these tasks during lyceum lessons. I feel a bit guilty for that." 
What is interesting in this data is that teachers provided more negative aspects regarding the effects of PT on teachers' time and effort. A majority of teachers conceded that they had to spend a good deal of time and energy for PT which in turn affected their preparation for lyceum lessons. Although teachers avoided evaluating their own experience, a few of them admitted that they had heard of other teachers who prioritized PT and saved their energy during regular lessons.

Students' interviews indicated that students were mostly content with their core subjects. However, one student reported that teacher-tutors did not have a full dedication to teaching during regular lessons as in PT, while teachers of non-specialized subjects were not concerned much about teaching. He explained that teachers of 'secondary subjects' did not bother working with students the whole lesson, instead teachers allowed them to do their tasks or tutoring homework after explaining a new topic which can be indications of teacher malpractices such as energy-saving and professional negligence in regular classes.

In short, part of the teachers sometimes felt 'demoralized' or 'stressed out' when they encountered conflictual situations with students and thought they were teaching 'in vain' when PT 'complicated their teaching practices' or could not find a solution for ineffective teaching practices. However, the rest of the teachers did not suppose PT to be an obstacle for their teaching, instead, they regarded tutoring as a mechanism to consolidate the knowledge taught at lyceum and strengthen their professional skills.

\subsection{Impact of PT on students' learning}

All teachers believed that PT was efficient to increase students' knowledge and observed as most of their students improved their academic grades. The respondents enumerated several factors why students learned better in PT. First of all, teachers noted that students had stronger motivations for learning as they had certain ambitions to receive PT, such as entering universities, going abroad or attaining certain qualifications. Moreover, they believed that students were more disciplined and had a higher responsibility owing to their parents' spending. Lastly, PT was deemed to have a more flexible learning environment to meet each student's individual needs. This factor was reiterated in students' interviews too, in which students stated that more individual time with the teacher/tutor compared to classroom environment better suited their learning and understanding, therefore they expressed satisfaction from their tutoring classes.

However, not all teachers agreed that PT was efficient for learners. One teacher, for instance, stated that she had students with different learning abilities and motivations, therefore she thought it was rather challenging to achieve each student's progress. Some teachers reported that they would quit tutoring with students who lacked interest in a subject or were not capable of mastering given tasks because teachers did not want parents to waste their money when tutoring did not fit with their children's capacities. 
A few other teachers thought that tutoring was ineffective when parents pushed students to take extra classes. For example, one teacher disapproved of parents who forced their children to go for tutoring and blamed tutors when the results fell short of their expectations. An English language teacher, on the other hand, argued that tutoring was not always as efficient as she expected. She stated that low-achieving students mostly performed in the same way as in regular lessons and PT had no significant effect on their academic grades. She also noted that "they usually go for tutoring, for their parents want them to do so, or they follow their friends who are performing well in lyceum lessons". This indicates that parental factors and peer influence also had an important role in students' choice of PT.

Moreover, most teachers indicated that PT negatively affected students' grades in non-core subjects, since their attention was directed at studying two or three specific subjects only. A good reference was made by an Astronomy teacher, who noted that "some may excel at Mathematics, but they lag way behind in other subjects". Interviews with students also corroborated this, as half of the students experienced a drop in their grades from non-core subjects. One student's comment on the quality of regular lessons, for instance, was quite surprising: "Students are concerned about three subjects from their specialization, as for other subjects it is not even interesting for them whether they are satisfactory or not." Similarly, another student also asserted that students "partly study non-core subjects only for grades, not for acquiring knowledge”. Because 'secondary-level' subjects were weighted less than core subjects, students did not bother to study them which eventually influenced their grades too.

\section{Discussion}

The main objective of this study was to determine the teachers' overall attitudes towards PT. The findings showed that all teachers, including principals, supported PT and thought that it was useful and necessary for students' academic achievements. Even the teachers who were not serving as tutors were pragmatic and encouraged their students to take additional classes. Interviews indicated that the primary concern of teachers was the progression of students to HE institutions. These findings are consistent with those of Altinyelken (2013), Wang and Bray (2016), and Sun (2017), in which teachers were in support of students' taking tutoring because of stiff competition in examinations.

In contrast to Turkey or Hong Kong, teachers in Uzbekistan are engaged in tutoring themselves and their dual roles inevitably affect their attitudes too. According to Ball and Youdell (2007), when the private sector is brought into public schools it forms "a new moral environment for both consumers and producers" (p. 52). This means that both teachers and students will face a "culture of self-interest" or "survivalism" (ibid.) and particularly teachers are likely to experience transformations in their identities as teachers' professional values clash with market values. This 
96 notion was echoed in the interviews which revealed that teachers' attitudes were different towards students with tutoring and without. To be precise, they perceived students taking PT as more 'active' and 'diligent' compared to students who did not. This suggests that teachers may not be treating all students equally regardless of their mixed ability (commonality value).

Similarly, a majority of teachers considered tutoring their students as a normal or positive procedure. In previous studies, this type of tutoring was referred to as educational corruption (see Brehm \& Silova, 2014; Dawson, 2009). However, it is difficult to assess teachers' tutoring their students to be completely unethical, because many teachers noted that they refrained from treating students better for receiving tutoring and called such acts as 'unfair' or 'wrong'. Similar patterns were observed in Kobakhidze's (2014) study in Georgia, where teachers' tutoring their own students became a typical practice like in Uzbekistan, and she argued that such practice is "not necessarily a form of corruption" as there were many teachers who were fully dedicated to their profession (p. 455).

Additionally, a sympathetic attitude of teachers towards students from disadvantaged families can be construed as an example of moral values. Nearly all teachers stated that they tutored students from low-income families free of charge or with discounts. Some teachers even noted that they did tutoring not only for making a profit but also 'out of the goodness of their heart'. These findings are consistent with the findings reported by Kobakhidze (2014) in which she categorized such teachers as "Robin Hood teachers" (p. 465).

By contrast, the teachers of non-core subjects and those who were not tutoring presented contrasting viewpoints towards PT. Although they considered that PT is necessary for the current situation due to the complexity of examinations, they were more concerned about its negative effects on students' attitudes toward non-specialized subjects as they became more disruptive and negligent during their classes.

The scale of tutoring was another important aspect of the phenomenon: overall $95 \%$ of the sampled students responded that they received PT over the last 12 months. This includes students who were currently not taking any tutoring but had attended during the 12 months prior to the survey. The intensity and frequency of tutoring might vary across different groups, yet on the whole the attendance was remarkably high in both lyceums. Although the data are incomparable due to the size of the sample and differences in target population, they provide some insights about the pervasiveness of tutoring in the context of Uzbekistan. Similar trends were observed in the findings of Silova and Kazimzade's (2006) survey in Azerbaijan which indicated that $90 \%$ of first-year university students were found to have received private tutoring (including preparatory courses) before entering the university. Likewise, the figures in neighboring countries, such as Kazakhstan (64.8\%), Tajikistan (60\%) and Kyrgyzstan (52.5\%), were relatively high (Silova, 2009d). 


\subsection{Influence of PT on teaching and learning}

The findings highlighted that teachers mostly considered PT to be useful for teaching and learning even though they disclosed multiple issues related to tutoring which have negative effects on the quality of education. Nevertheless, it is important to bear in mind the possible biases in the responses of teachers as their viewpoints are contingent upon their perceived 'new identity'. As discussed above, teachers' dual roles, as both teachers and tutors represent two different (professional and market) values, and the mixture of these affected their way of thinking and beliefs. For instance, half of the teachers believed that PT made their teaching easier because they thought the tutoring role enabled them to expand their knowledge, develop their test-solving skills and strengthen their pedagogical experience. Some teachers even identified PT not as an obstacle, but as part of the preparation for regular lessons. Again, this manifests teacher-tutors' acquired 'culture of self-interest' - an "orientation toward the internal well-being of ... its members and a shift away from concern with more general social and educational issues within [community]" (Ball \& Youdell, 2007, p. 52).

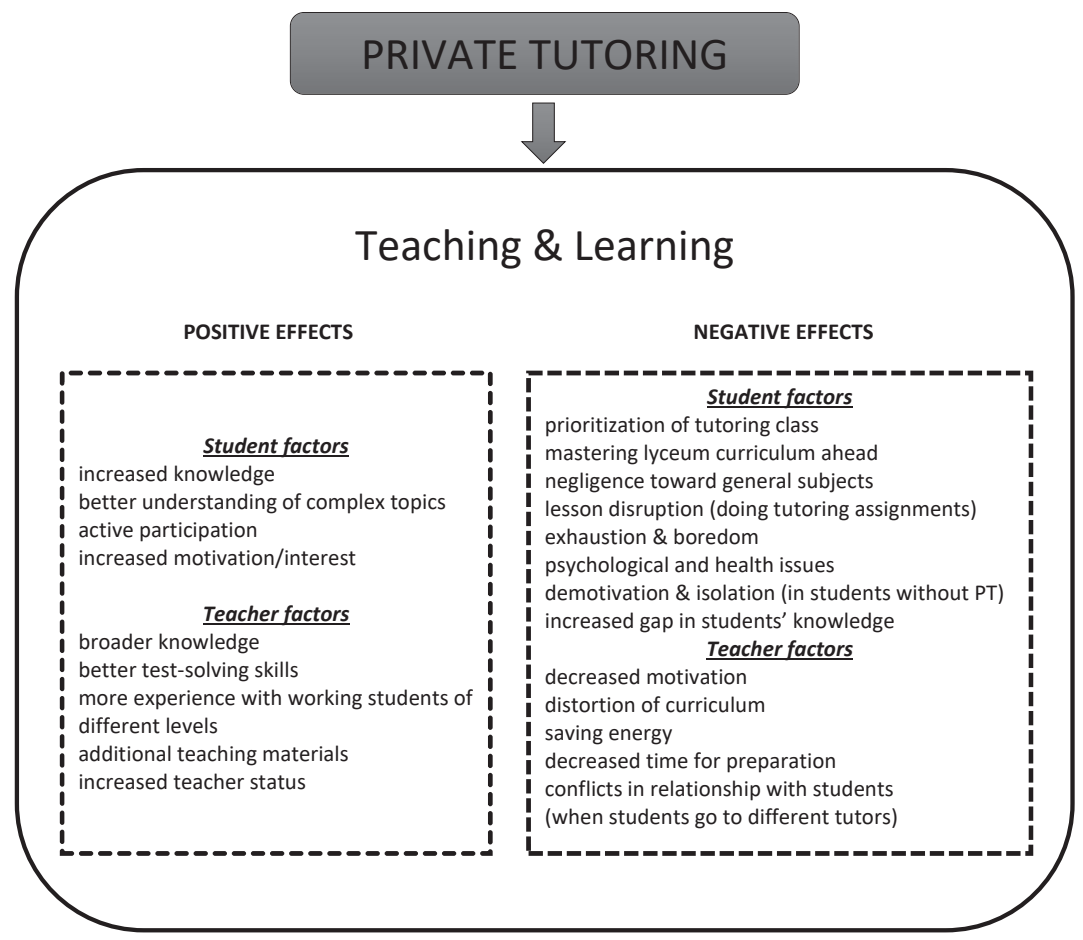

Figure 2 Influence of PT on teaching and learning 
Bray (2011) remarked that the practice of teachers' involvement in PT, particularly teachers' tutoring their students, might cause the risks of decreased motivation and effort in teaching at mainstream schools, favoritism, and other unethical practices. Although the teachers ignored the issues of favoritism and corruption in their practices, a few teachers did not deny the existence of such malpractices in their examples of other teachers. In the same way, teachers refused to prioritize PT, but they admitted to preparing additional materials for tutoring, such as test banks, audio-visual aids, and manuals.

Likewise, Loveluck (2012) asserted that teachers' engagement in PT deters teachers to fulfil their lesson plans. This was consistent with the findings of current research which showed that teachers spent a great deal of time and effort towards PT and could not prepare well for lyceum lessons. Some teachers were reported to save energy during regular lessons while some others intentionally decreased teaching hours to have more time for tutoring. This suggests that tutoring had a significant impact on teachers' teaching practices, even though they were reluctant to admit the negative influences.

More issues were visible in non-core subjects. Due to the complex nature of entrance examinations, students' dependence on PT increased. This might have enhanced students' learning from specialized subjects but it caused a loss of interest in learning other subjects. In the same way, PT adversely affected the quality of teaching in non-core subjects. Student interviews unveiled that teachers of these subjects usually explained the new topic in the first half of the lesson and then allowed students to do their tutoring assignments for the remaining time. This can be explained as an 'erosion' of teachers' professional values since they became less considerate about the repercussions of PT (Figure 2).

\subsection{Emergence of formal shadow education within mainstream schooling}

One of the significant findings to emerge from this study was the establishment of a tutoring centre inside the academic lyceum (as was observed in AL2). The distinctive feature of this tutoring centre was that it operated within the premises of the lyceum and under the management of the principal, and the tutoring was delivered mainly by lyceum teachers. This can be regarded as the confluence of mainstream education with shadow education or the emergence of 'formal' shadow education within mainstream schooling. The study refrains to discuss the legal bases of establishing a tutoring centre within the public sector because it was beyond the research purpose. However, the teachers' involvement in the running of the tutoring centre might affect their commitment to the teaching profession. For instance, some teachers stopped being employed as teachers in the lyceum and were fully employed as tutors in the tutoring centre, while some others became part-time teachers to increase their tutoring hours. 
On the one hand, the establishment of the tutoring centre provided the students with official tutoring services within the academic lyceum. On the other hand, it enabled the teachers to engage with tutoring in the first half of the day when they did not have lessons. This may lead to the prioritization of tutoring and decreased devotion towards the teaching profession. The integration of private sector in public education, in this sense, can be a good example of Ball and Youdell's (2007) privatization concepts on "transformation of education from a public good to private commodity" (p. 53) as well as transformation of identities: Principal to manager, and a teacher to a technician (p. 45).

\subsection{Dependence on PT}

The teachers' overall attitudes towards PT indicates teachers' increasing reliance on PT rather than their teaching capacities or professionalism. This was evident in teachers' supporting students to take extra classes from their subjects. Even, teachers as parents encouraged their children to receive PT. However, it is worth noting that students' dependency on PT was more psychological. Among students, it became a common belief that without PT they cannot succeed in entrance examinations. Therefore, nearly all students received PT irrespective of their level of knowledge.

Kwo and Bray (2011) also mentioned teachers' partial reliance on tutoring to consolidate some parts of the curriculum in Hong Kong. In Cambodia, on the other hand, public schools were found to cover only the part of the national curriculum during school time, which allowed teachers to supplement the remaining content during tutoring classes for a fee (Brehm \& Silova, 2014), which illustrates an explicit form of teacher corruption. In Uzbekistan, however, teacher tutors reported that they fully covered the state curriculum and even utilized their tutoring materials in classroom lessons as additional sources. Therefore, PT was viewed as a tool to supplement the lyceum program with the syllabus of secondary schools and vocational colleges. It seems the dependence on PT in academic lyceums derived from the complexity of examination tests and divergence of the lyceum curriculum from entrance examinations. Student interviews also revealed their satisfaction from lyceum lessons but they thought that the curriculum was not adequate for high-stakes examinations.

\subsection{The shift of the role from mainstream to shadow: Examination-oriented education}

In the current context of academic lyceums, PT has taken a form of alternative education to substitute mainstream education in preparing students for high-stakes examinations. There is a general assumption among parents that the quality of education at lyceums is substantially higher as compared to secondary schools or vocational colleges, and lyceum teachers are deemed the most qualified of all. Notwithstanding, many teachers regard lyceum lessons as not very efficient in preparing 
students for entrance examinations, owing to limited teaching hours, an excessive number of students, and a diversity of students' levels. Given the shortcomings of academic lyceums in meeting individual needs for learning, PT has taken the role of preparing students for entrance examinations. Therefore, for students, the mastery of the required knowledge has become viable only through PT.

During a 2013 TED Talk speech titled How to Escape Education's Death Valley, renowned educationalist Sir Ken Robinson stated, "the dominant culture of education has come to focus on not teaching and learning, but testing". Indeed, the pervasiveness of testing culture has been visible in education systems around the world, particularly in East Asian countries, such as China, South Korea, and Japan. In these countries, tutoring centres are considered a major competitor of mainstream schooling by promoting examination-oriented education (Kwok, 2004). In the context of Uzbekistan, similar trends have become visible after the introduction of a testing system for university admissions. However, unlike the aforementioned countries, in Uzbekistan mainly teachers took the role of providers of tutoring. This enabled hidden privatization to creep into mainstream schooling in the form of shadow education and "contribute[d] to the privatization of paths to educational attainment" (Dawson, 2010, p. 22). These statements verify that the landscape of public education had shifted under the influence of the market economy and neoliberal ideologies which focus mainly on examination results or performance outcomes rather than the broader goals of schooling. Therefore, a fundamental dilemma remains: whether or not students should keep receiving PT in line with mainstream schooling in academic lyceums, the place whose mission is to give deeper knowledge in specialized fields and prepare students for the next pillar of education.

\section{Conclusion}

PT is widespread globally and it has a growing nature which can be associated with marketization and privatization. This study outlined how the blurring of the private sector (shadow education) with the public sector affected the teaching and learning process and the attitude of educators. The findings from this study suggest that the emergence of shadow education in academic lyceums changed the nature of public schooling as well as transforming the identities of main stakeholders such as teachers, principals, and students. The prevalence of PT was strongly linked to the complexity of current entrance examination tests which increased the dependency of both teachers and students on PT. Despite multiple negative aspects of PT, teachers remained positive in their opinions and thought PT to be essential both for learning and teaching. For them, PT served as a survival mechanism, which brought certain benefits along with exacerbating existing problems.

Finally, number of important limitations need to be acknowledged. First, the current study has only examined the perspectives of lyceum teachers in Samarkand region, and with a small sample size, caution must be applied, as the findings might 
not be transferable to the country level. The data of the quantitative component is not representative of the whole upper secondary level in the region, because the focus of the study is restricted to Grade 12 students in two academic lyceums (vocational colleges are excluded).

The study has also limitations associated with timing. The data was collected in 2017, in a period of political transfer, when radical reforms were introduced in public education system by the current President Shavkat Mirziyoyev. The shift to former 11-year education system from K12 education was completed in 2019. The quantitative data was grounded on the previous system (Grade 12 students), nevertheless the challenge of PT is still applicable to the current system due to the growing scale of the phenomenon. In addition, communication with lyceum principals and tutoring teachers were also filled with issues in guaranteeing an accurate description of the issue. As topics of private tutoring, education quality and teacher salary were politically sensitive, in some occasions administrators and participants might have been unwilling to provide a fully accurate picture or did not want to disclose information during the interview. Therefore, the researcher added 2 vice-principals and 2 teachers who did not engage in PT to the initial sample size to maintain the balance and objectivity in data aggregation and compare the variations.

In spite of these limitations, this research serves as the first attempt to empirically explore the nature and implications of private tutoring in Uzbekistan. It is a baseline study. Thus, the findings of the study may serve as valuable information for stake-holders and policy-makers in the country to evaluate the implications of private tutoring in a rational way when making education policy decisions.

\section{References}

Altinyelken, H. K. (2013). The demand for private tutoring in Turkey: Unintended consequences of curriculum reform. In M. Bray, A. E. Mazawi, \& R. G. Sultana (Eds.), Private tutoring across the Mediterranean: Power dynamics and implications for learning and equity (pp. 187-204). Sense Publishers.

Bagdasarova, N., \& Ivanov, A. (2009). Private tutoring in Kyrgyzstan. In I. Silova (Ed.), Private supplementary tutoring in Central Asia: New opportunities and burdens (pp. 119-142). IIEP-UNESCO.

Baker, D. P., \& Le Tendre, G. K. (2005). National differences, global similarities: world culture and the future of schooling. Stanford University Press.

Ball, S. J., \& Youdell, D. (2007). Hidden privatisation in public education. Education International.

Bray, M. (1999). The shadow education system: private tutoring and its implications for planners [Fundamentals of Educational Planning No. 61]. IIEP-UNESCO.

Bray, M. (2003). Adverse effects of private supplementary tutoring: Dimensions, implications and government responses. UNESCO.

Bray, M. (2006). Private supplementary tutoring: comparative perspectives on patterns and implications. Compare, 36(4), 515-530.

Bray, M. (2009). Confronting the shadow education system: What government policies for what private tutoring? IIEP-UNESCO. 
Bray, M. (2011). The challenge of shadow education: Private tutoring and its implications for policy makers in the European Union. European Commission.

Bray, M., \& Kobakhidze, M. N. (2014). The global spread of shadow education: Supporting or undermining qualities of education? In D. B. Napier (Ed.), Qualities of education in a globalized world (pp. 185-200). Sense Publishers.

Bray, M. , \& Kobakhidze, M. N. (2015). Evolving ecosystems in education: The nature and implications of private supplementary tutoring in Hong Kong. Prospects, 45, 465-481.

Bray, M., \& Kwo, O. (2014). Regulating private tutoring for public good: Policy options for supplementary education in Asia. Comparative Education Research Centre (CERC), The University of Hong Kong.

Bray, M., \& Kwo, O. (2015). Designing and implementing mixed approaches to shadow education research: Experiences and lessons in Hong Kong. In M. Bray, O. Kwo, \& B. Jokić (Eds.), Researching private supplementary tutoring: Methodological lessons from diverse cultures (pp. 149-178). The University of Hong Kong and Springer.

Bray, M., Kwo, O., \& Jokić, B. (2015). Introduction. In M. Bray, O. Kwo, \& B. Jokić (Eds.), Researching private supplementary tutoring: Methodological lessons from diverse cultures (pp. 3-19). Comparative Education Research Centre (CERC), The University of Hong Kong and Springer.

Bray, M., \& Kwok, P. (2003). Demand for private supplementary tutoring: conceptual considerations, and socio-economic patterns in Hong Kong. Economics of Education Review 22, 611-620.

Bray, M., \& Silova, I. (2006). The private tutoring phenomenon: International patterns and perspectives. In I. Silova, V. Būdiene, \& M. Bray (Eds.), Education in a hidden marketplace: monitoring of private tutoring (pp. 27-40). Open Society Institute.

Brehm, W. C., \& Silova, I. (2014). Hidden privatization of public education in Cambodia: Equity implications of private tutoring. Journal for Educational Research Online, 6(1), 94-116.

Cohen, L., Manion, L., \& Morrison, K. (2007). Research methods in education (6th ed). Taylor \& Francis, Routledge.

Dawson, W. (2009). The tricks of the teacher: Shadow education and corruption in Cambodia. In S. P. Heyneman (Ed.), Buying your way into heaven: Education and corruption in international perspective (pp. 51-74). Sense Publishers.

Dawson, W. (2010). Private tutoring and mass schooling in East Asia: Reflections of inequality in Japan, South Korea, and Cambodia. Asia Pacific Education Review, 11, 14-24.

Foondun, R. A. (2002). The issue of private tuition: An analysis of the practice in Mauritius and selected South-East Asian countries. International Review of Education, 48(6), 485-515.

Hays, J. (2008). Education in Uzbekistan. Retrieved September 9, 2020, from http: / factsand details.com/central-asia/Uzbekistan/sub8_3f/entry-4733.html

Ireson, J. (2004). Private tutoring: How prevalent and effective is it? London Review of Education, 2(2), 109-122.

Kalikova, S., \& Rakhimzhanova, Z. (2009). Private tutoring in Kazakhstan. In I. Silova (Ed.), Private supplementary tutoring in Central Asia. New opportunities and burdens (pp. 93-118). IIEP-UNESCO.

Kazimzade, E., \& Lepisto, E. (Eds.) (2010). Drawing the line: Parental informal payments for education across Euro-Asia. Open Society Institute.

Kobakhidze, M. N. (2014). Corruption risks of private tutoring: Case of Georgia, Asia Pacific Journal of Education, 34(4), 455-475.

Kobakhidze, M. (2018). Teachers as tutors: Shadow education market dynamics in Georgia. The University of Hong Kong, CERC and Springer.

Kodirov, Sh., \& Amonov, N. (2009). Private tutoring in Tajikistan. In I. Silova (Ed.), Private supplementary tutoring in Central Asia. New opportunities and burdens (pp. 143-166). IIEP-UNESCO.

Kwo, O., \& Bray, M. (2011). Facing the shadow education system in Hong Kong. IIAS Newsletter [University of Leiden, International Institute for Asian Studies], 56(20). http://old.iias. asia/article/facing-shadow- education-system-hong-kong 
Kwok, P. L. Y. (2004). Examination-oriented knowledge and value transformation in East Asian cram schools. Asia Pacific Education Review, 5(1), 64-75.

Liu, J. (2015). How a research instrument changed in different settings: Methodological lessons from adaptation and adjustment. In M. Bray, O. Kwo, \& B. Jokić (Eds.), Researching private supplementary tutoring: Methodological lessons from diverse cultures (pp. 247-259). Comparative Education Research Centre (CERC), The University of Hong Kong and Springer.

Loveluck, L. (2012, March). Education in Egypt: Key challenges [Background paper]. Chatham House.

Matiashvili, A., \& Kutateladze, N. (2006). Georgia. In I. Silova, V. Būdiene, \& M. Bray (Eds.), Education in a hidden marketplace: monitoring of private tutoring (pp. 191-209). Open Society Institute.

Murawska, B., \& Putkiewicz, E. (2005). Private tutoring in Poland. The Institute of Public Affairs.

Onwuegbuzie, A. J., \& Collins, K. M. (2007). A typology of mixed methods sampling designs in social science research. The Qualitative Report, 12(2), 281-316.

Onwuegbuzie, A. J., \& Johnson, R. B. (2006). The validity issue in mixed research. Research in the Schools. 13(1), 48-63.

Popa, S., \& Acedo, C. (2006). Redefining professionalism: Romanian secondary education teachers and the private tutoring system. International Journal of Educational Development, 26, 98-110.

President Decree of the Republic of Uzbekistan No. 2829 (President Decree No. 2829). (2017, March 14). On measures to further improve the activities of secondary special and vocational education institutions. https: //lex.uz/docs/3133119

Pussurmanova, G. (2017). Nature and factors influencing high school students and parents' demands for private supplementary tutoring in Kazakhstan [Unpublished master's thesis]. Nazarbayev University. https: / / nur.nu.edu.kz/bitstream/handle/123456789/2568/Gulzada _Pussurmanova.pdf?sequence=1\&isAllowed=y

Robinson, K. (2013, May). How to escape education's death valley. TED talks education. http:// youtu.be/wX78iKhlnsc

Shafiq, M. N. (2002). The economic burden of private tutoring expenses on households in developing countries: The case of Bangladesh. Paper presented at the annual conference of the Comparative \& International Education Society. Orlando, Florida, USA.

Silova, I. (Ed). (2009a). Introduction. In I. Silova (Ed.), Private supplementary tutoring in Central Asia. New opportunities and burdens (pp. 27-32). IIEP-UNESCO.

Silova, I. (2009b). Global patterns and post-socialist realities in the private tutoring market: Conceptual and methodological considerations. In I. Silova (Ed.), Private supplementary tutoring in Central Asia. New opportunities and burdens (pp. 33-47). IIEP-UNESCO.

Silova, I. (2009c). Education and post-socialist transformations in Central Asia. In I. Silova (Ed.), Private supplementary tutoring in Central Asia. New opportunities and burdens (pp. 49-68). IIEP-UNESCO.

Silova, I. (2009d). Examining the scope, nature and implications of private tutoring in Central Asia. In I. Silova (Ed.), Private supplementary tutoring in Central Asia. New opportunities and burdens (pp. 69-92). IIEP-UNESCO

Silova, I. (2010). Private tutoring in Eastern Europe and Central Asia: Policy choices and implications. Compare, 40(3), 327-344.

Silova, I., \& Bray, M. (2006a). The context: societies and education in the post-socialist transformation. In I. Silova, V. Būdiene, \& M. Bray (Eds.), Education in a hidden marketplace: monitoring of private tutoring (pp. 41-60). Open Society Institute.

Silova, I., \& Bray, M. (2006b). The hidden marketplace: Private tutoring in former Socialist countries. In I. Silova, V. Būdiene, \& M. Bray (Eds.), Education in a hidden marketplace: monitoring of private tutoring (pp. 71-98). Open Society Institute.

Silova, I., \& Kazimzade, E. (2006). Azerbaijan. In I. Silova, V. Būdiene, \& M. Bray (Eds.), Education in a hidden marketplace: monitoring of private tutoring (pp. 113-141). Open Society Institute. 
104 Sun, M. Y. F. (2017). Private supplementary tutoring in a Hong Kong primary school: What Chinese and English teachers think about the phenomenon, and how tutoring may affect dimensions of teacher professionalism [Unpublished master's thesis]. The University of Hong Kong.

Teddlie, Ch., \& Tashakkori, A. (2003). Major issues and controversies in the use of mixed methods in the social and behavioral sciences. In A. Tashakkori \& Ch. Teddlie (Eds.), Handbook of mixed methods in social and behavioral research (pp. 3-50). Sage.

United Nations Educational, Scientific and Cultural Organization (UNESCO). (2017). Global education monitoring report, 2017/8: Accountability in education - Meeting our commitments. UNESCO.

Wang, D. \& Bray, M. (2016). When whole-person development encounters social stratification: Teachers' ambivalent attitudes towards private supplementary tutoring in Hong Kong. The Asia-Pacific Education Researcher, 25(5), 873-881.

Sherzod Khaydarov Westminster International University in Tashkent 12 Istikbol Street, Tashkent 100047, Uzbekistan skhaydarov@wiut.uz 